GA-A23979

\title{
HIGH POWER LONG PULSE PERFORMANCE OF THE DIII-D GYROTRON INSTALLATION
}

\author{
by \\ J. LOHR, Y.A. GORELOV, R.W. CALLIS, H.J. GRUNLOH, \\ J.J. PEAVY, R.I. PINSKER, D. PONCE, R. PRATER, \\ and R.A. ELLIS, III
}




\section{DISCLAIMER}

This report was prepared as an account of work sponsored by an agency of the United States Government. Neither the United States Government nor any agency thereof, nor any of their employees, makes any warranty, express or implied, or assumes any legal liability or responsibility for the accuracy, completeness, or usefulness of any information, apparatus, product, or process disclosed, or represents that its use would not infringe privately owned rights. Reference herein to any specific commercial product, process, or service by trade name, trademark, manufacturer, or otherwise, does not necessarily constitute or imply its endorsement, recommendation, or favoring by the United States Government or any agency thereof. The views and opinions of authors expressed herein do not necessarily state or reflect those of the United States Government or any agency thereof. 


\title{
HIGH POWER LONG PULSE PERFORMANCE OF THE DIII-D GYROTRON INSTALLATION
}

\author{
by \\ J. LOHR, Y.A. GORELOV, R.W. CALLIS, H.J. GRUNLOH, \\ J.J. PEAVY, R.I. PINSKER, D. PONCE, R. PRATER, \\ and R.A. ELLIS, III
}

†Princeton Plasma Physics Laboratory

This is a preprint of a paper presented at the 12th Joint Workshop on Electron Cyclotron Emission and Electron Cyclotron Resonance Heating, May 13-16, 2002, in Aix-en-Provence, France, and to be published in the Proceedings.

\author{
Work supported by \\ the U.S. Department of Energy \\ under Contract Nos. DE-AC03-99ER54463 \\ and DE-AC02-76CH03073
}




\title{
HIGH POWER LONG PULSE PERFORMANCE OF THE DIII-D GYROTRON INSTALLATION
}

\author{
JOHN LOHR,${ }^{\dagger}$ Y.A. GORELOV,${ }^{\dagger}$ R.W. CALLIS,${ }^{\dagger}$ H.J. GRUNLOH, ${ }^{\dagger}$ J.J. PEAVY,,$\dagger$ \\ R.I PINSKER,${ }^{\dagger}$ D. PONCE,${ }^{\dagger}$ R. PRATER,${ }^{\dagger}$ AND R.A ELLIS $\ddagger$ \\ †General Atomics, P.O. Box 85608, San Diego California, 92186-5608 USA \\ ¥Princeton Plasma Physics Laboratory, Princeton, New Jersey 08543-0451
}

\begin{abstract}
At DIII-D, five $110 \mathrm{GHz}$ gyrotrons are operating routinely for $2.0 \mathrm{~s}$ pulses at generated power levels $\geq 750 \mathrm{~kW}$ per gyrotron. A sixth gyrotron is being installed, which should bring the generated power level to $>4 \mathrm{MW}$ and the injected power to about 3.0 MW. The output power now can be modulated by the plasma control system to fix $T_{e}$ at a desired value. The system is being used as a tool for control of current diffusion, for current profile control and other experiments leading to advanced tokamak operation.
\end{abstract}

\section{Introduction}

The DIII-D gyrotron complex now comprises six $110 \mathrm{GHz}$ gyrotrons of which five are in routine operation and one is just being brought on-line. Three of these ${ }^{1}$ are equipped with artifically grown diamond windows and are specified to be capable of generating Gaussian beams with $10 \mathrm{~s}$ pulse length at $1.0 \mathrm{MW}$. After about $3 \mathrm{~s}$, all of the gyrotron components have reached thermal equilibrium, so that, in principle, should it be required by the experiment, pulses longer than $10 \mathrm{~s}$ could be generated by these gyrotrons. The remaining three gyrotrons ${ }^{2}$ have boron nitride output windows and generate broad beams to keep the window peak power loading to acceptable levels. For this group of gyrotrons, window heating, up to about $1000^{\circ} \mathrm{C}$, limits the pulse length to $2.0 \mathrm{~s}$ at about $750 \mathrm{~kW}$ generated rf power. Phase correcting focusing mirrors reform a Gaussian beam for injection into the transmission line, but $15 \%-18 \%$ of the rf power is lost in this process.

The complete system includes the gyrotrons plus high voltage power supplies, transmission line components, dummy loads, polarizers, waveguide switches, launchers and controls, all of which must be qualified for full pulse length at maximum power. This paper describes the performance of the system components at maximum pulse length and power achieved to date.

The DIII-D Plasma Control System has been used to modulate the output power of the gyrotron system in order to force a desired time evolution of the electron temperature at a specific location in the plasma. The ability to affect the electron temperature profile opens new experimental possibilities. In the first application of this capability, the temperature profile was feedback controlled to affect the current penetration early in the tokamak discharge.

\section{Gyrotron Performance}

The CPI gyrotrons are being extended in power and pulse length to their maximum ratings of $1.0 \mathrm{MW}$ at $10.0 \mathrm{~s}$. To date these tubes have all achieved $1.0 \mathrm{MW}$ for pulses several milliseconds in duration and $500-600 \mathrm{~kW}$ for $10.0 \mathrm{~s}$ in testing at the manufacturer. For these long pulse tests, the currents were limited by the power supply to $26 \mathrm{~A}$, about $65 \%$ of the rated peak value. Maximum generated power and pulse length achieved to date for the gyrotrons in the DIII-D system are tabulated below.

\footnotetext{
$1_{1}$ Manufactured by Communications and Power Industries, CPI, Palo Alto, CA, USA.

${ }^{2}$ Manufactured by Gycom, Nizhny Novgorod, Russia.
} 
Table 1. Operational performance of the Gycom and CPI gyrotrons in service at DIII-D

\begin{tabular}{lcccc}
\hline \multicolumn{1}{c}{ Gyrotron } & Type & MFG & Pgen $(\mathbf{k W}) /$ Length $(\mathbf{s})$ & V(kV)/l(A) \\
\hline Gycom 1 & Centaur & Gycom & $800 / 2.0$ & $74 / 34$ \\
Gycom 2 & Monomakh & Gycom & $750 / 2.0$ & $69 / 30$ \\
Gycom 3 & Centaur & Gycom & $750 / 2.0$ & $69 / 30$ \\
CPI-P2 & VGT 8110 & CPI & $510 / 10.0,950 / 5.0$ & $80 / 40$ \\
CPI-P3 & VGT 8110 & CPI & $600 / 10.0,750 / 8.0$, & $80 / 40$ \\
& & & $1042 / .01$ & \\
CPI-P1 & VGT 8110 & CPI & $530 / 10.0,1030 / .01$ & $80 / 40$ \\
\hline
\end{tabular}

The CPI-P1 gyrotron suffered a failure in the aluminum diffusion bond on the diamond window and has been repaired and returned to DIII-D. Installation is nearly complete for this gyrotron, but only CPI test performance data are available.

The power supply configuration for the system is shown schematically in Fig. 1. Two Gycom gyrotrons, Gycom 2 and Gycom 3, are powered from a converted neutral beam power supply with parallel Eimac 9009 tetrodes feeding two Eimac 9009 tetrodes each of which powers one of the Gycom tubes. Two CPI gyrotrons, CPI-P2 and CPI$\mathrm{P} 3$, are being operated from the same modulator/regulator tetrode, an $\mathrm{ABB} C \mathrm{CQK}$ 200-4. These gyrotrons have been operated simultaneously for $5.0 \mathrm{~s}$ at $78 \mathrm{kV}$ and $38 \mathrm{~A}$ each from this power supply. The third pair of gyrotrons, also operated using a single ABB CQK 200-4 tetrode is a voltage mismatch between Gycom 1, a Gycom tube operating at $73 \mathrm{kV}$ and CPI-P1, a CPI tube operating at $78-80 \mathrm{kV}$, requiring that the $\mathrm{CPI}$ tube be operated at the lower voltage. A third modulator/regulator tetrode is being added to the Gycom 2/Gycom 3 power supply system to provide independent modulation and voltage control for Gycom 1. No regulation instability or incompatibilities have been experienced with any of these configurations.

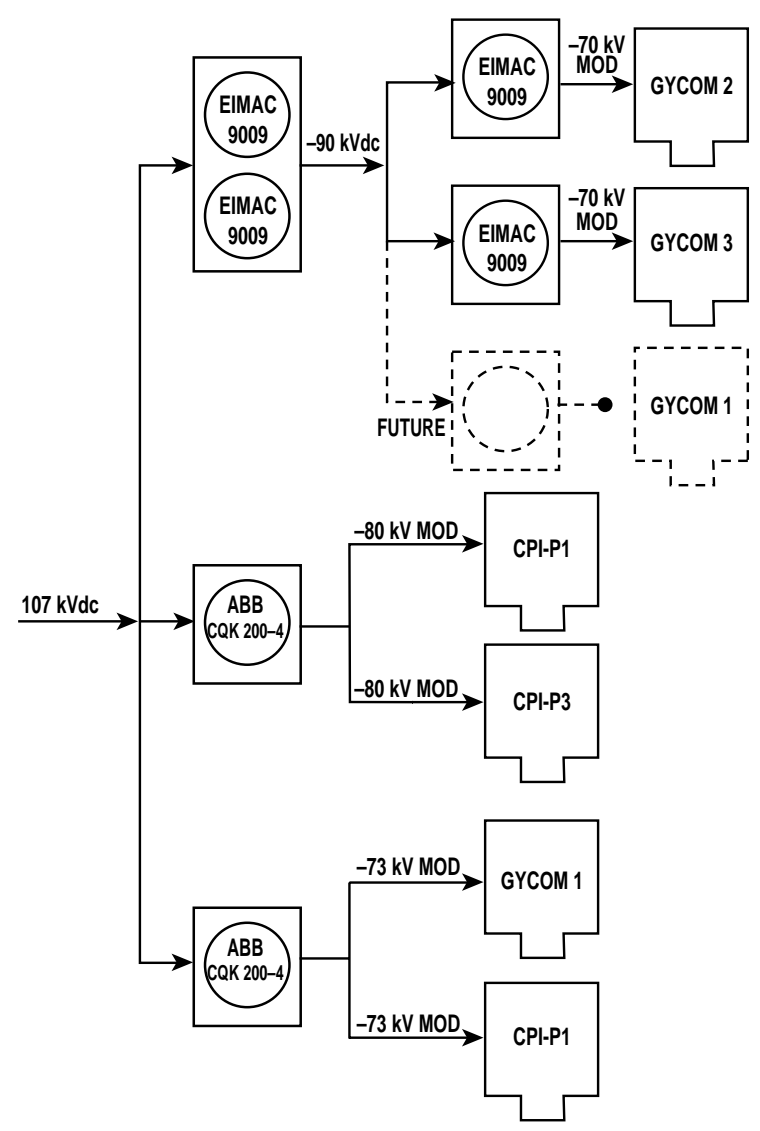

Fig. 1. Block diagram of the power supply configuration for the DIII-D gyrotron complex. Two pairs of gyrotrons are powered in parallel by single modulator/regulators, and a third pair is powered by a modulator/regulator pair in series with individual modulator tetrodes for each of the gyrotrons.

The generated rf power of the gyrotrons heats their output windows. Calorimetric measurements of this heating, combined with knowledge of the absorption coefficient, provide a measurement of the power. For the CPI-P2 gyrotron, CPI measured an absorption coefficient of $0.22 \%$ for short pulses and $0.27 \%$ for long pulses. The measured window losses for the CPI-P2 gyrotron are shown in Fig. 2. There is considerable scatter in the data for short pulses owing to the low window absorbed energy. The values converge to about $2.5 \mathrm{~kW}$ at 5 s pulse lengths, implying about $1 \mathrm{MW}$ through the window.

Another method of estimating the rf production is to obtain the difference between the input electrical power and the electron beam power dissipated in the collector. In Fig. 3 a representative subset of the data for highest power operation shows between 1.0 and about 1.6 MW for this difference. This method gives an upper bound to the rf power generated. 
Since the power exiting the gyrotron through the output window may be in high order modes other than Gaussian, the best measure of the power that will reach the plasma is to collect the power in a dummy load after the rf beam is inserted into the waveguide by the matching optics unit (MOU). The dummy load is a combination of a fast acting mode conversion load, which absorbs about $75 \%$ of the power and a standard inconel tank load, which absorbs the remaining $25 \%$. Over a range of gyrotron tuning combinations and pulse lengths, the data indicate an average power in the two dummy loads of about $750 \mathrm{~kW}$. About $70 \mathrm{~kW}$ is typically dissipated in the MOU. The bulk of the data represent pulses for which the gyrotron was tuned for reliable performance. Points at substantially higher power, up to nearly $1.0 \mathrm{MW}$ generated, were the result of attempts to push the power higher. In Fig. 4 these results are summarized.

The plasma provides an extremely black load with very low reflected rf power. The quality of the dummy load combination can be evaluated by comparing the MOU absorbed power for pulses which were directed to the tokamak with dummy load pulses. In Fig. 5 such a comparison is made for the CPI-P3 gyrotron. Although there is an indication for short pulses that some power could be reflected back into the MOU from the dummy loads, for pulses longer than about $500 \mathrm{~ms}$ this difference is insignificant. Some fraction of the power reflected back to the MOU could pass back through the window contributing twice to the window heating and biasing the window power estimate to higher values.

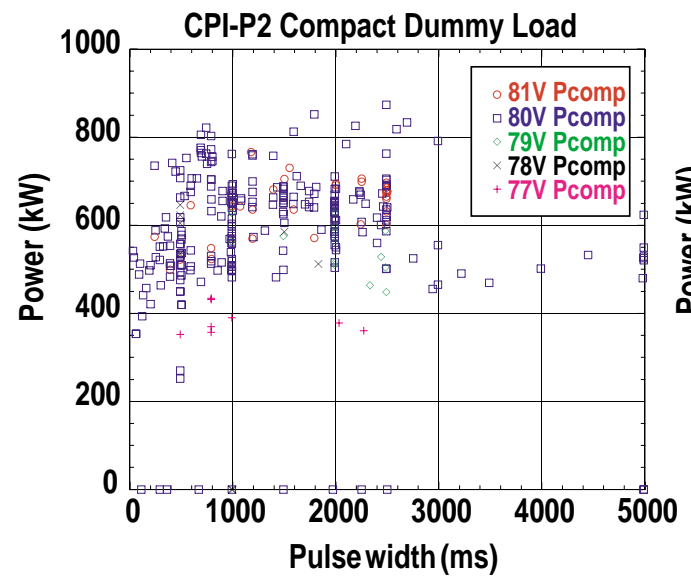

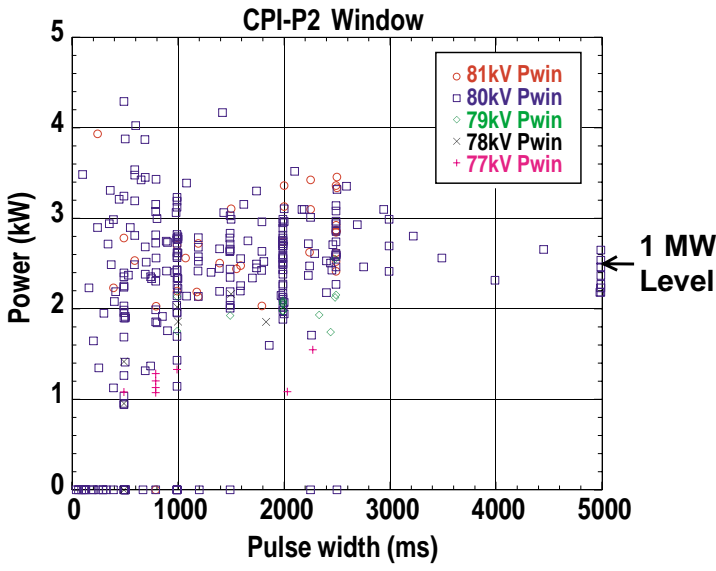

Fig. 2. Window power loading for CVD diamond windows is about $2.5 \mathrm{~kW}, 0.25 \%$.

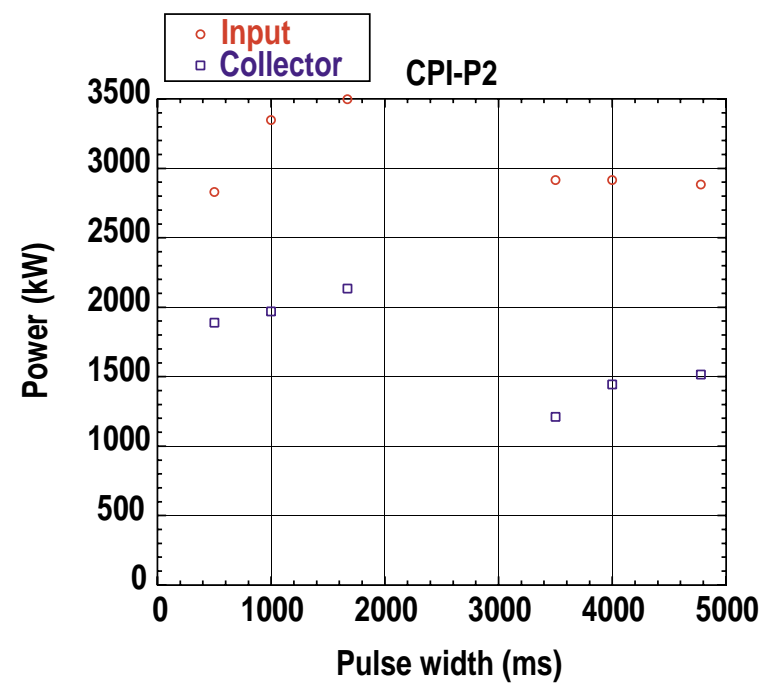

Fig. 3. Input electrical power compared with the collector power for the CPI-P2 gyrotron. The difference between the two powers indicates $r f$ production and electron beam heating of the internal components.

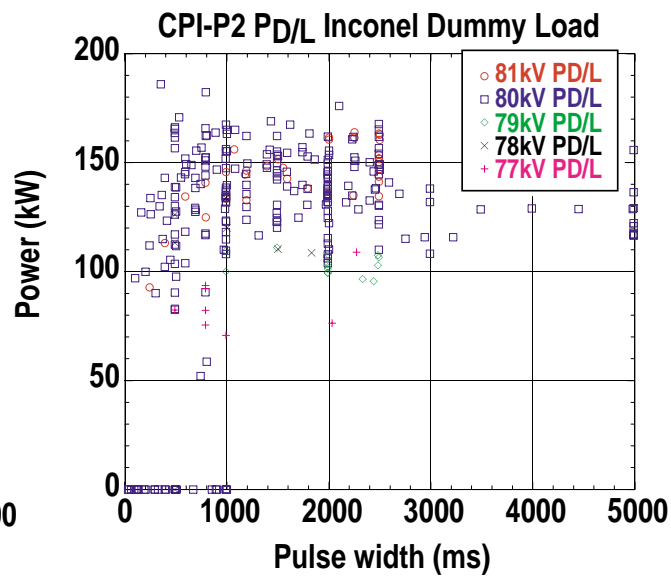

Fig. 4. Performance summary for the CPI-P2 gyrotron manufactured by CPI. The gyrotron is equipped with a diamond output window and produces a Gaussian rf beam. The compact dummy load, a mode conversion load, absorbs about $75 \%$ of the incident power and the inconel dummy load absorbs the reminder. 
Historically, long pulse operation of high power gyrotrons has been limited by heating of the output windows. Net performance of these same gyrotrons was also reduced by the need to reduce the peak power loading of the output windows by spreading the footprint of the output beam as it exited the tube. It proved to be difficult to recover all the $\mathrm{rf}$ power in these spread beams to Gaussian beams suitable for injection into transmission lines. In Figs. 6 and 7 these difficulties are illustrated. Figure 6(a) shows the window power loading of the Gycom 2 gyrotron with BN window as a function of pulse length. The average window loading of $30 \mathrm{~kW}$ represents about $4 \%$ of the generated power. By comparison, Fig. 6(b) for the CPIP2 diamond window, which absorbs about $0.25 \%$ of the transmitted power, shows about $2.5 \mathrm{~kW}$ loading over a range of gyrotron beam voltages. This low absorption for diamond also makes it possible to extract a Gaussian beam from the gyrotron directly, requiring no conversion prior to injection into the transmission line. An indication of the efficiency increase thus realized can be seen by comparing the MOU loading for CPI-P2 and Gycom 2, which amounts to greater than a factor of two when the moderately higher average output power of CPI-P2 is taken into account. In Fig. 7, a comparison between the MOU loadings for the two gyrotrons is presented. Additional efficiency is realized with the CPI-P2 system, which uses a single coupling mirror compared with the mirror pair used for Gycom 2.

The diamond windows not only have lower rf absorption than ceramics such as BN, they also have considerably higher thermal conductivity. This means that, given appropriate cooling design, the diamond windows will rapidly achieve thermal equilibrium leading to the possibility of $\mathrm{cw}$ operation. Infrared measurement of the peak window temperature of the CPI-P2 gyrotron for a $5.0 \mathrm{~s}$ long pulse and approximately $1 \mathrm{MW}$ transmitted rf power is shown in Fig. 8. The temperature is constant after about $3 \mathrm{~s}$ at a modest value which keeps the diamond about a factor of three below the allowable stress limit of $350 \mathrm{MPa}$ [1].
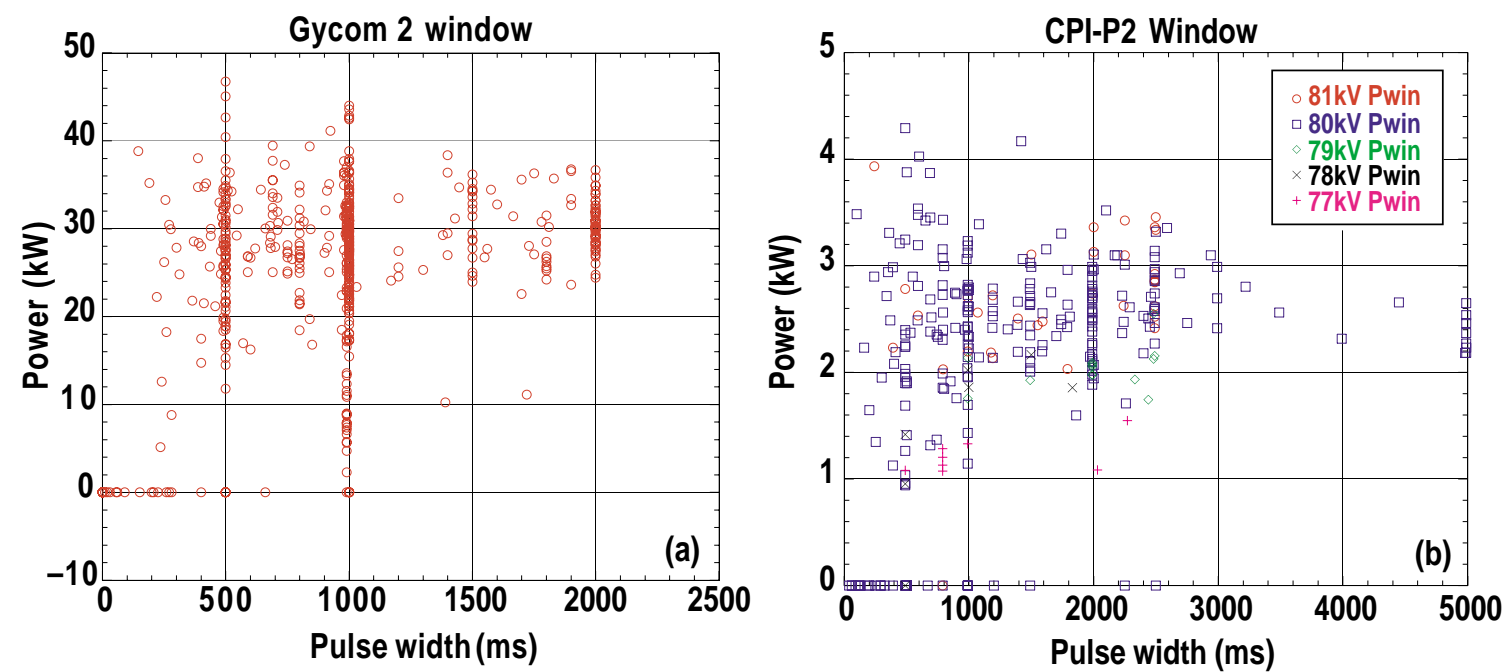

Fig. 6. Window power loading for BN ceramic windows is about $30 \mathrm{~kW}, 4 \%$, compared with 2,5 $\mathrm{kW}, 0.25 \%$, for diamond. 

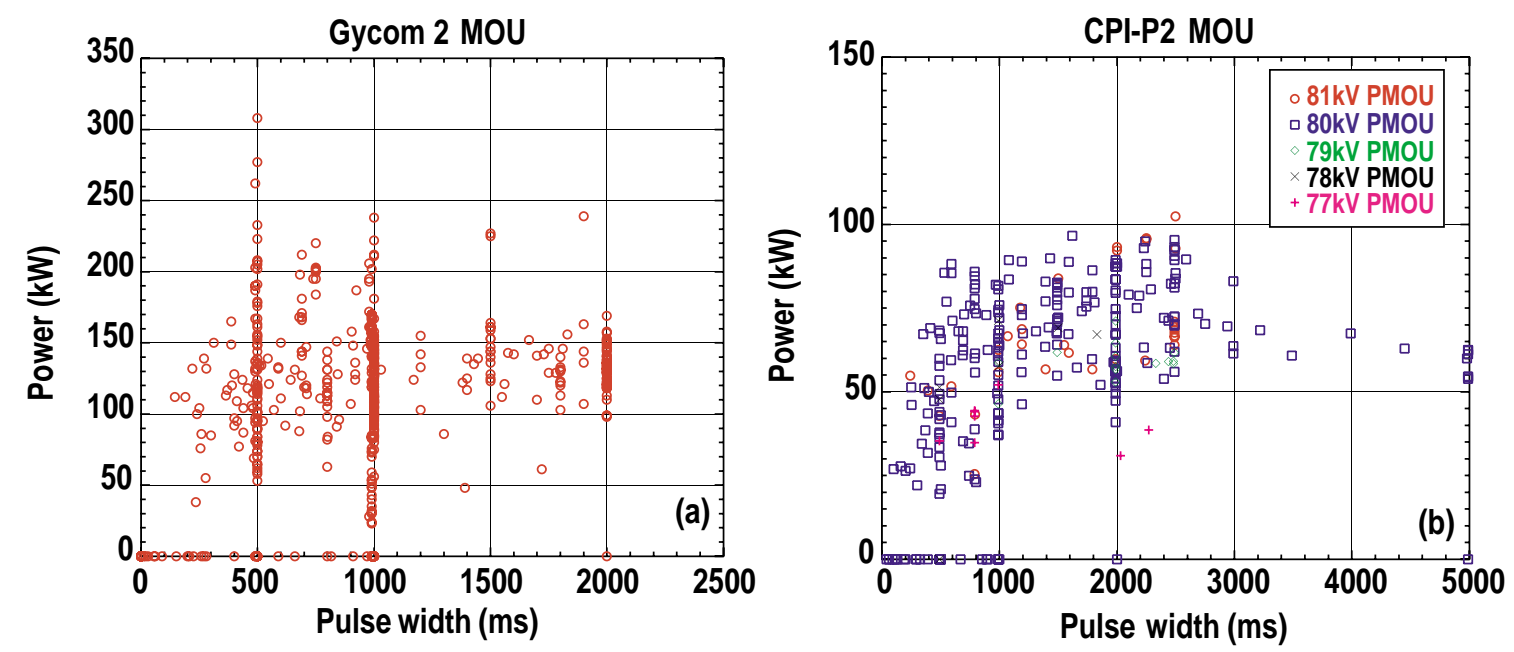

Fig. 7. Waveguide coupling is more than twice as efficient for gyrotrons which produce Gaussian beams directly than for the broadened beams necessary for BN windows.

When the rf beams are switched from the dummy loads to the tokamak, the calorimetrically measured dummy load power is corrected for transmission line losses to infer the power injected into DIII-D. As many as 14 miter bends are included in the lines, which can be up to $100 \mathrm{~m}$ in length. Each standard miter contributes $0.95 \%$ loss and each of the two polarizing miters contributes $1.5 \%$ to the line losses. For the longest lines, an additional $6 \%$ is lost in the corrugated circular waveguide giving a total loss estimate of about $-1 \mathrm{~dB}$ for the worst case. This was verified by a direct low power measurement on the worst case line as indicated in Fig. 9. A swept source with $0.4 \%$ sweep range was used to inject a signal at the output of the MOU, which was detected after the last miter bend at the tokamak. The detected signal was compared with propagation over a short path to derive the attenuation. A resistive wall waveguide section provided damping of offmode waves and the frequency sweep ensured that a cavity resonance did not introduce errors. A permanently installed power monitor for the last miter bend before the tokamak is under development.

The calorimetry database provides an opportunity to examine the power loading of various components of the different gyrotrons as a function of gyrotron pulse length. Any trends, particularly those indicating higher loading as the pulse

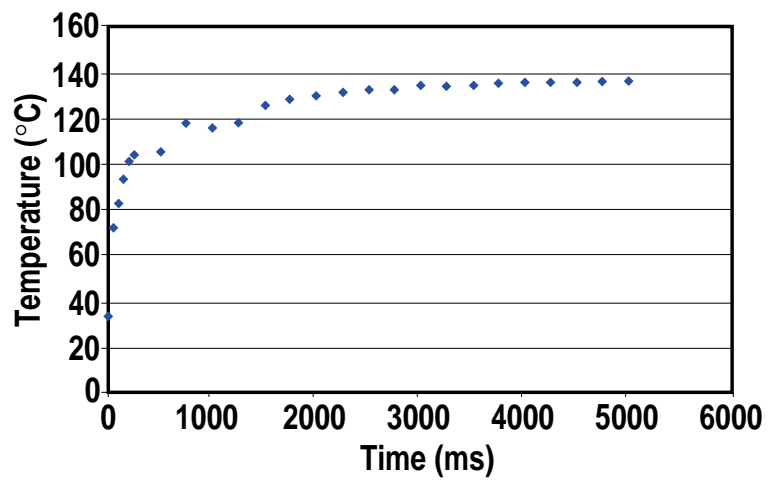

Fig. 8. The time dependence of the CPI-P2 diamond window peak temperature for a 5.0 s pulse at about $1 \mathrm{MW}$ transmitted power. The window reaches equilibrium after about $3 \mathrm{~s}$ and the peak stress is a factor of three below the yield point.

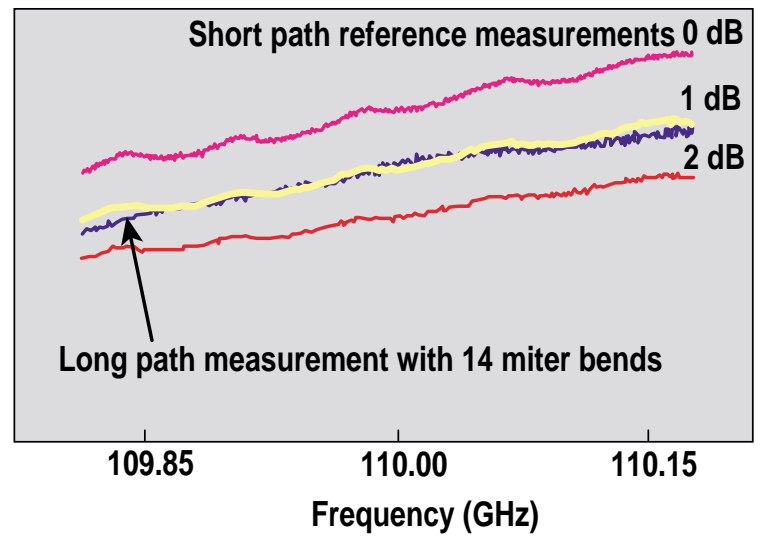

Fig. 9. The measured loss in the worst case transmission line is about $-1 \mathrm{~dB}$. The line is about $100 \mathrm{~m}$ in length and has 14 miter bends, including a polarizer pair.

length is increased, can be noted and evaluated for determining the ultimate performance limits for the tubes and the system components. 


\section{Feedback Control of the RF Power}

Fusion science experiments depend on control of plasma parameters such as shape and density. A recent development on DIII-D has been the feedback control of the gyrotron output power by the DIII-D plasma control system for temperature control. The control system compares the time dependent ECE signal from a particular point in the plasma to a target waveform and derives an error signal which is used to generate a modulation command for the gyrotrons. The modulation command is applied to the signal controlling the output of the high voltage power supply, which causes the electron beam energy to be varied over a range, typically about $+0 \%,-20 \%$, of the normal operating voltage of the gyrotron. Without retuning, the gyrotron output is a monotonic function of voltage, therefore the control algorithm does not go unstable.

An example of feedback control is shown in Fig. 10(a) [2]. An arbitrary target waveform, in this case slowly increasing with triangular teeth, was compared with the electron temperature at $\rho=0.4$ and all four operational gyrotrons were modulated by the control system, heating near this flux surface. The actual temperature tracked the target very well during temperature increases and with less fidelity during decreases when the energy confinement time holds up the response.

The first application of this new capability was to use controlled heating of the electrons to affect the rate of plasma current penetration early in the discharge. In Fig. 10(b) three fully controllable temperature evolutions result in three different time evolutions of the plasma current density.
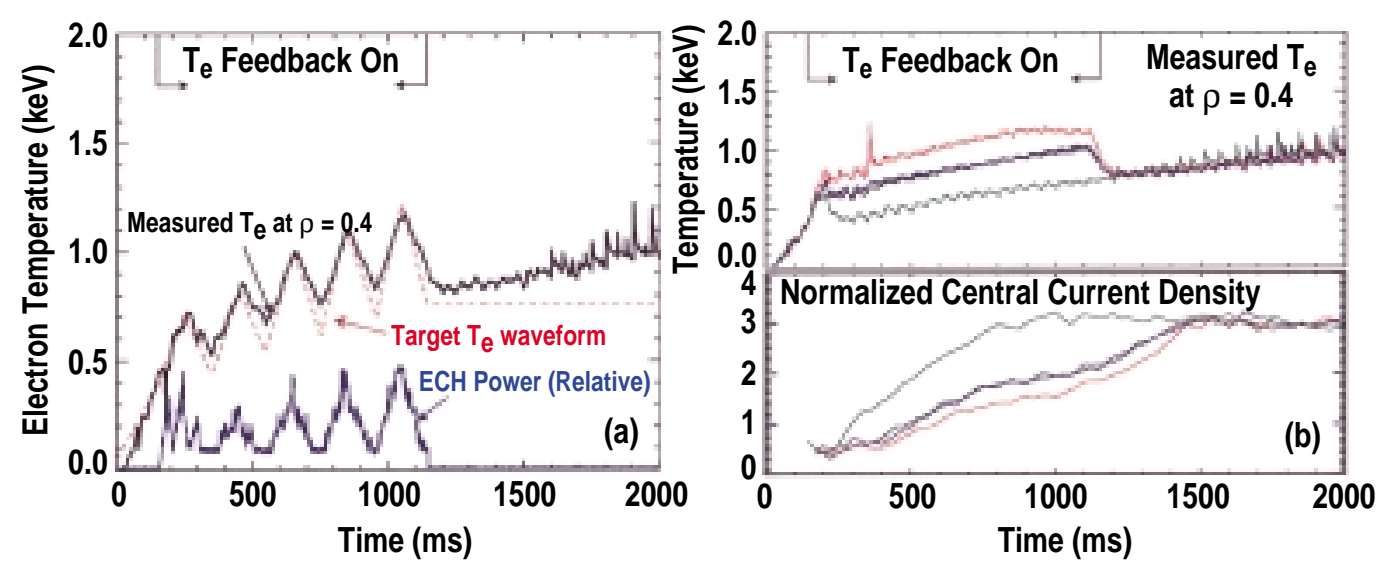

Fig. 10. Feedback control of the output power of the gyrotrons permits regulation of the rate of current diffusion early in the discharge. On the left a target temperature is tracked by the system and on the right the capability is exercised to produce a time evolution of temperature, which determines the current diffusion.

\section{Current Drive}

As system upgrades have become available, new experiments have been made possible. Five high power gyrotrons are now able to inject at least $2.5 \mathrm{MW}$ for $2.0 \mathrm{~s}$ pulses. The higher power plus installation of a second articulating launcher capable of both poloidal and toroidal scanning has now enabled systematic current profile modifications to be performed and studied leading to advanced tokamak (AT) operation. Although the total power is considerably less than required for optimized AT performance, proof of principle experiments have been completed.

Significant modification to the current density profile with co- and counter- ECCD has been achieved. In Fig. $11 \mathrm{q}(\mathrm{r})$ profiles have been plotted for co-ECCD at $\rho=0.2$ [3]. The modification of the $\mathrm{j}(\mathrm{r})$ profile is clearly observable and of sufficient magnitude that ECCD can now begin to be used as a tool for the AT program. 

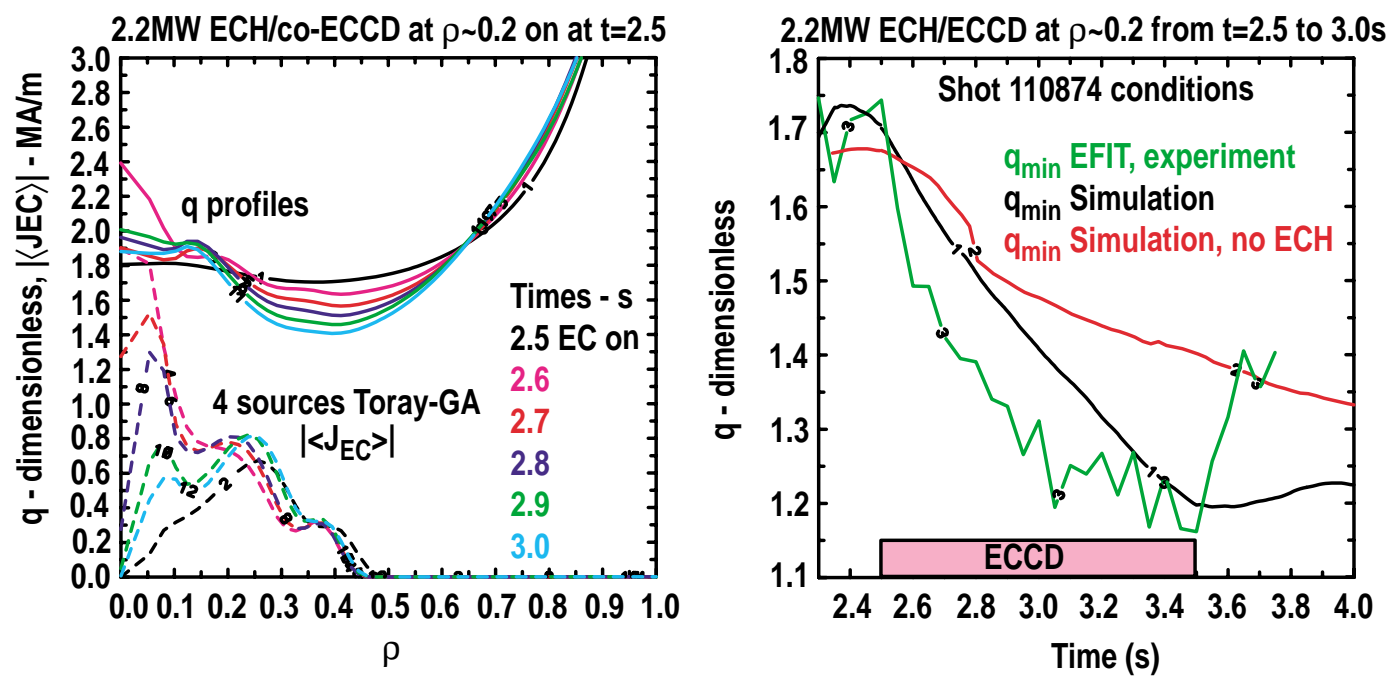

Fig. 11. Measured evoluation of $q(r)$ profiles for co-ECCD. The driven current profiles are plotted in the lefthand figure. in the righthand figure $q_{\min }$ is plotted as a function of time. The qmin value is lower than expected from simulations and returns to the no ECH value after termination of the rf pulse.

\section{Summary}

Five high power $110 \mathrm{GHz}$ gyrotrons are installed and available for experiments on the DIII-D tokamak. Generated rf power is greater than $3 \mathrm{MW}$ and injected power is greater than 2.5 MW. A sixth gyrotron is being commissioned and is available for limited experimental service. System performance, in particular the thermal performance of the diamond gyrotron windows, has been stable and indicates that the DIII-D complex can support a new series of experiments leading to studies of advanced tokamak operation. Feedback control of the output power of the installation provides a new control tool, which is being used to study and modify current diffusion and the steady-state $q(r)$ profile.

\section{Acknowledgment}

Work supported by U.S. Department of Energy under Contract No. DE-AC0399ER54463 and DE-AC02-76CH03073.

\section{References}

[1] Y. Gorelov et al., "Infrared Monitoring of $110 \mathrm{GHz}$ Gyrotron Windows At DIII-D," this conference.

[2] M.R. Wade, private communication.

[3] T.A. Casper, private communication. 